\title{
Mechanism Analysis and Optimum Control of Negative Airgap Eccentricity Effect for in-wheel Switched Reluctance Motor Driving System
}

\section{Zhaoxue Deng}

Chongqing Jiaotong University

Xu Li ( $\square$ lixu3238@mails.cqjtu.edu.cn )

Chongqing Jiaotong University https://orcid.org/0000-0002-5763-0578

Xingquan Li

Chongqing Changan Automobile Co Ltd

Shuen Zhao

Chongqing Jiaotong University

Hanbing Wei

Chongqing Jiaotong University

\section{Research Article}

Keywords: switched reluctance motor, in-wheel motor driving system, airgap eccentricity, electric vehicle

Posted Date: November 5th, 2021

DOI: https://doi.org/10.21203/rs.3.rs-1002988/v1

License: (c) (1) This work is licensed under a Creative Commons Attribution 4.0 International License. Read Full License 


\title{
Mechanism analysis and optimum control of negative airgap eccentricity effect for in-wheel switched reluctance motor driving system
}

\author{
Zhaoxue Deng ${ }^{1}, \mathrm{Xu} \mathrm{Li}^{1,}{ }^{*}$, Xingquan $\mathrm{Li}^{2}$, Shuen $\mathrm{Zhao}^{1}$, Hanbing Wei ${ }^{1}$ \\ 1 School of Mechatronics and Automotive Engineering, Chongqing Jiaotong University, Chongqing, China \\ 2 State Key Laboratory of Vehicle NVH and Safety Technology, Chongqing Changan Automobile Co., Ltd, China \\ *Corresponding author: $\mathrm{Xu} \mathrm{Li}$ \\ Email address: 1ixu3238@mails.cqjtu.edu.cn
}

\begin{abstract}
This paper analyzes the generation and influence mechanism of negative airgap eccentricity effect for in-wheel switched reluctance motor (SRM) driving system, and proposes an optimum control strategy to achieve cooperative optimal performance between in-wheel motor driving system and electric vehicle (EV). Firstly, the electromagnetic characteristic of SRM under airgap eccentricity is studied based on electromagnetic coupling model and circuit driving equation. Then, the negative effect of airgap eccentricity on the in-wheel SRM driving system is analyzed in timefrequency domain combined on the excitation characteristics of unbalanced radial force. Finally, an independent current chopping control strategy for in-wheel SRM driving system based on vehicle vibration feedback is proposed, and the controller parameters are optimized by interpolation. The simulation results show that the proposed optimum control strategy can improve the driving torque while restrain the unbalanced radial force, and effectively suppress the negative airgap eccentricity effect of in-wheel motor driving system. This study starts from the dynamics relationship between SRM, in-wheel motor driving system and EV, and lays a theoretical foundation for solving the negative dynamic effect of in-wheel motor driving system.
\end{abstract}

Keywords: switched reluctance motor, in-wheel motor driving system, airgap eccentricity, electric vehicle

\section{Introduction}

Vehicle electrification has become an inevitable trend in the development of automobile industry due to the profound adjustment of global energy framework[1-3]. In particular, the in-wheel motor driving $\mathrm{EV}$ has the comprehensive engineering prospect by virtue of efficient mechanical transmission and rapid control response[4,5]. The dynamics response of electric vehicle (EV) is determined by the in-wheel motor, a pivotal driving component mounted directly on the wheel[6,7]. Among different in-wheel driving motor types, the rotor of switched reluctance motor (SRM) has neither windings nor permanent magnets, and its torque is generated by the tendency of magnetic circuit to choose the minimum reluctance structure[8], which embraces the potential of application and popularization in the field of EV $[9,10]$.

On the other hand, the special structure of SRM also leads to nonlinear electromagnetic characteristic, which will cause the serious problems in vibration and noise, become the obstacle to its further development $[11,12]$. It is mentionable that the radial electromagnetic force between stator and rotor is the primary factor that brings about vibration and noise[13,14]. In recent years, researchers have carried out abundant researches on radial electromagnetic force based on the virtual displacement principle and the Maxwell stress tensor[15,16]. These studies focused on the electromagnetic characteristic of SRM under ideal mechanical conditions, and did not fully consider 
the variety on the electromagnetic characteristic after airgap eccentricity occurs.

The airgap eccentricity of SRM caused by external disturbances such as road excitation and driving behavior are unavoidable, as shown in figure 1 (a), and the resulting imbalance of radial electromagnetic force will produce residual unbalanced radial force[17,18]. The negative airgap eccentricity effect of in-wheel motor driving system caused by unbalanced radial force will further affect EV dynamic performance[19,20]. It is significant to clarify the influence mechanism of unbalanced radial force on the negative airgap eccentricity effect of the in-wheel motor driving system[21]. However, most of the existing researches analyzed its response features from the time domain or frequency domain alone, and lack of integrated analysis in the time and frequency domain combining with the excitation characteristic of radial electromagnetic force.

To suppress the negative airgap eccentricity effect for in-wheel motor driving system, the existing research mainly focused on the active suspension, the multi-objective optimization and driving control[22-24]. Active suspension can improve ride comfort and handling stability performance for EV[25], but the increase of unsprung mass will reduce the mechanism stability of driving system. On the contrary, while the multi-objective optimization can build up the output response of the in-wheel motor driving system obviously, the improvement of EV dynamics performance is limited[26]. Taken together, this negative airgap eccentricity effect can be suppressed by driving control. Looking for a reasonable driving control strategy to meet the requirements of vehicle speed change in real time is still a scientific problem actively explored by various scholars.

In view of the above research shortages, this paper focuses on the mechanism analysis and optimum control of negative airgap eccentricity effect of in-wheel SRM driving system, so as to realize the cooperative optimal performance between in-wheel motor driving system and EV. First, the electromagnetic characteristic of SRM under airgap eccentricity was studied combined on electromagnetic coupling model and circuit driving equation. Then, the negative effect of airgap eccentricity on the in-wheel SRM driving system was analyzed in time-frequency domain based on the excitation characteristics of unbalanced radial force. Furthermore, an independent current chopping control strategy for SRM based on vehicle vibration feedback was proposed, and the controller parameters were optimized by interpolation in real time to achieve cooperative optimal performance between in-wheel motor driving system and EV. Finally, some important conclusions were summarized in the section 5 .

\section{Modeling and analysis of SRM}

The output response of in-wheel motor driving system is directly affected by the SRM. This section analyzes the electromagnetic characteristic and output response of SRM under airgap eccentricity by establishing electromagnetic coupling model and circuit driving euqation.

\section{1 electromagnetic coupling model}

Fourier series fitting is a common method to obtain the electromagnetic characteristic of SRM. The original data required for fitting can be obtained by experimental measurement or finite element analysis. In this paper, the four-phase 8/6 external rotor SRM as shown in figure 1 (b) is adopted as the research object[27]. The external rotor motor structure can be installed in the wheel to directly driving the vehicle. All scructure parameters are listed in appendix A. 
(a)

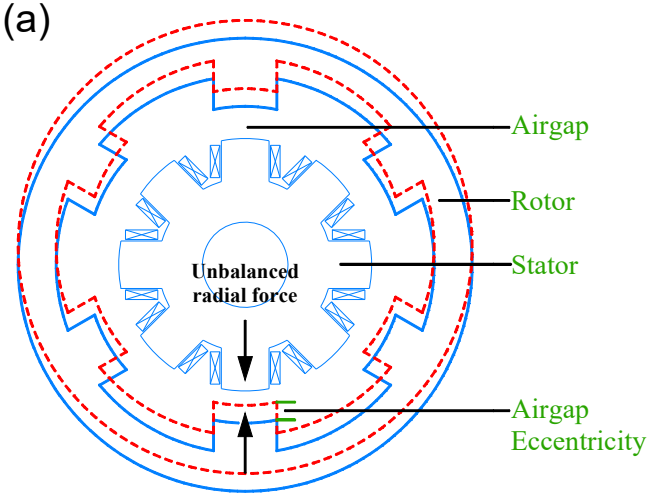

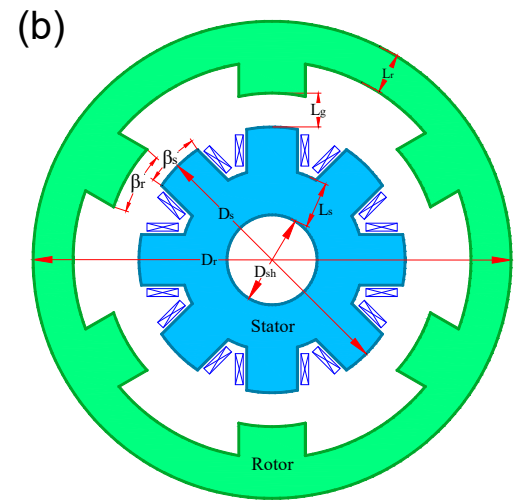

Fig. 1. Switched reluctance motor.

(a) airgap eccentricity; (b) external rotor motor structure.

The aligned position of salient pole and rotor groove is defined as the initial position, and the rotor angular displacement of SRM under this position is $0^{\circ}$. As the rotor rotates half pole pitch, the center line of stator salient pole and rotor salient pole coincide, which is the aligned position. At this time, the winding inductance $L(\theta, i)$ can be expanded by Fourier series[28,29] as follows.

$$
\begin{aligned}
L(\theta, i) & =L_{0}(i)+L_{1}(i) \cos \left(N_{r} \theta+\varphi_{1}\right)+\sum_{n=2,3, \cdots}^{\infty} L_{n}(i) \cos \left(n N_{r} \theta+\varphi_{n}\right) \\
& =\sum_{n=0}^{\infty} L_{n}(i) \cos \left(n N_{r} \theta+\varphi_{n}\right)
\end{aligned}
$$

where $\varphi_{n}=n \pi$. The coefficients of the Fourier series can be derived from the winding inductance of the stator and rotor at a particular position. These coefficients are calculated based on aligned inductance $L_{a}$, unaligned inductance $L_{u}$ and semi-aligned inductance $L_{m}$ in this paper.

$$
\left\{\begin{array}{l}
L_{0}(i)=\frac{1}{2}\left[\frac{1}{2}\left(L_{a}+L_{u}\right)+L_{m}\right] \\
L_{1}(i)=\frac{1}{2}\left(L_{a}-L_{u}\right) \\
L_{2}(i)=\frac{1}{2}\left[\frac{1}{2}\left(L_{a}+L_{u}\right)-L_{m}\right]
\end{array}\right.
$$

When the stator and rotor are in non-aligned position, the airgap is relatively large, which $L_{u}$ can be regarded as constant inductance, $L_{a}$ and $L_{m}$ can be expressed by the polynomial of winding current. Single phase winding inductance $L(\theta, i)$ of SRM can be expressed as follows.

$$
\begin{aligned}
L(\theta, i) & =\sum_{n=0}^{\infty} L_{n}(i) \cos \left(n N_{r}+\varphi_{n}\right) \\
& =\frac{1}{2}\left[\cos ^{2}\left(N_{r} \theta\right)-\cos \left(N_{r} \theta\right)\right] \sum_{n=0}^{N} a_{n} i^{n}+\sin ^{2}\left(N_{r} \theta\right) \sum_{n=0}^{N} b_{n} i^{n}+\frac{1}{2} L_{u}\left[\left(\cos ^{2}\left(N_{r} \theta\right)+\cos \left(N_{r} \theta\right)\right]\right.
\end{aligned}
$$

where $a_{n}$ and $b_{n}$ are polynomial fitting coefficients. Furthermore, the integration of winding inductance about the current excitation can be solved to obtain the representation of the winding flux linkage as follows.

$$
\begin{aligned}
\psi(\theta, i) & =\int_{0}^{i} L(\theta, i) d i \\
& =\frac{1}{2}\left[\cos ^{2}\left(N_{r} \theta\right)-\cos \left(N_{r} \theta\right)\right] \sum_{n=1}^{N+1} c_{n} i^{n}+\sin ^{2}\left(N_{r} \theta\right) \sum_{n=1}^{N+1} d_{n} i^{n}+\frac{1}{2} L_{u} i\left[\cos ^{2}\left(N_{r} \theta\right)+\cos \left(N_{r} \theta\right)\right]
\end{aligned}
$$

where $c_{n}=a_{n-1} / n$ and $d_{n}=b_{n-1} / n$ is integral coefficient of $a_{n}$ and $b_{n}$ respectively. The 
winding inductance and flux linkage of SRM are shown in figure 2. based on the above analysis.

(a)

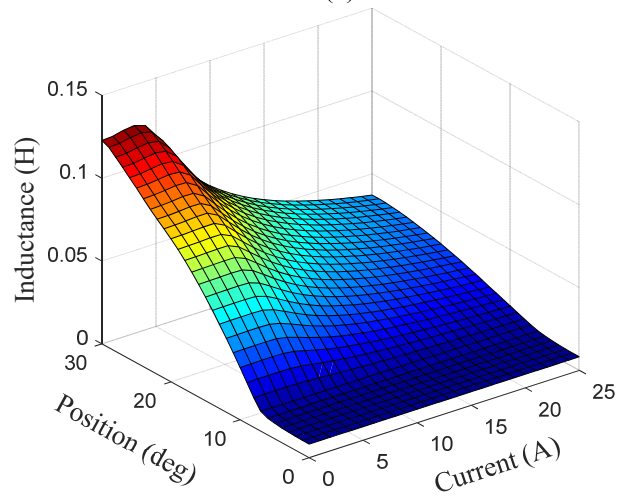

(b)

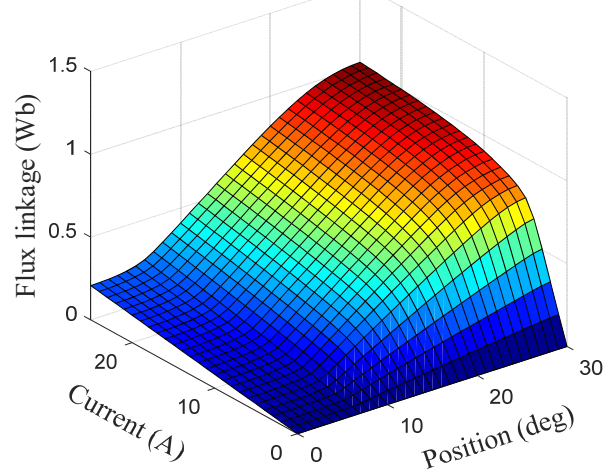

Fig. 2. Electromagnetic characteristic of SRM.

(a) inductance; (b) flux linkage.

Both inductance and flux linkage change nonlinearly with respect to rotating position and current excitation. The inductance reaches its maximum value at the aligned position and the current excitation is about 4A. Similarly, the flux linkage reaches its maximum value at the aligned position, but at the maximum current excitation.

According to the virtual displacement principle and electromagnetic energy conversion rule, the magnetostatic torque and radial electromagnetic force is that to solve the partial derivatives of winding magnetic co-energy with respect to rotating position and airgap length respectively.

$$
\left\{\begin{array}{l}
T_{m}=\left.\frac{\partial W_{m}}{\partial \theta}\right|_{i=\text { const }}=\int_{0}^{i} \frac{\partial \psi(\theta, i)}{\partial \theta} d i \\
F_{r}=\left.\frac{\partial W_{m}}{\partial l_{g}}\right|_{i=\text { const }}=\int_{0}^{i} \frac{\partial \psi(\theta, i)}{\partial l_{g}} d i
\end{array}\right.
$$

The magnetostatic torque and radial electromagnetic force are shown in figure 3. It is worth mentioning that although the magnetostatic torque at both the unaligned position and the aligned position is close to zero, the reasons for this phenomenon are different. In the unaligned position, the reluctance in the closed magnetic circuit is at the highest level of all rotating positions, resulting in lower winding magnetic co-energy and limited magnetostatic torque that can be generated. However, at the aligned position, the radial flux density between the stator and rotor is the largest while the tangential flux density is zero, and only radial mutual attraction exists between the two salient poles at this position.

(a)

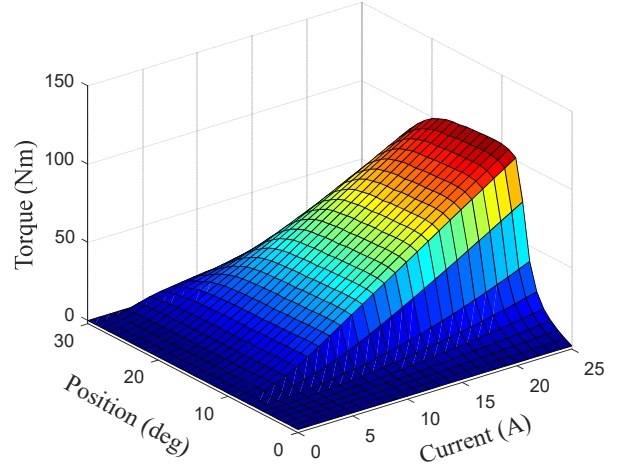

(b)

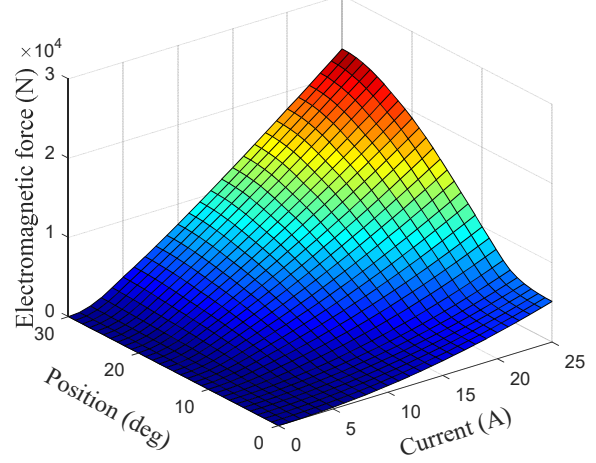

Fig. 3. Output response of SRM.

(a) magnetostatic torque; (b) radial electromagnetic force. 


\subsection{Circuit driving equation}

It can be found that the current excitation is one of the main factors affect the electromagnetic characteristic of SRM based on the above analysis, meanwhile, the current excitation is controlled by driving circuit parameters[30]. The asymmetric half bridge power converter adopted in this paper is shown in figure 4. According to Faraday's law of electromagnetic induction, the winding voltage balance equation of SRM can be expressed as follows.

$$
U_{k}=R_{k} i_{k}-e_{k}=R_{k} i_{k}+\frac{d \psi_{k}\left(\theta, i_{k}\right)}{d t}
$$

where $U_{k}, R_{k}, i_{k}$ and $e_{k}$ are the impressed voltage, resistance, current and induced electromotive force in phase $k$ winding respectively. Since both inductance and flux linkage are multivariate functions about rotating position and current excitation, the above equation can be further rewritten as follows.

$$
\begin{aligned}
U_{k} & =R_{k} i_{k}+\frac{\partial \psi_{k}\left(\theta, i_{k}\right)}{\partial i_{k}} \frac{d i_{k}}{d t}+\frac{\partial \psi_{k}\left(\theta, i_{k}\right)}{\partial \theta} \frac{d \theta}{d t} \\
& =R_{k} i_{k}+\left[L_{k}\left(\theta, i_{k}\right)+i_{k} \frac{\partial L_{k}\left(\theta, i_{k}\right)}{\partial t}\right] \frac{d i_{k}}{d t}+i_{k} \frac{\partial L_{k}\left(\theta, i_{k}\right)}{\partial \theta} \frac{d \theta}{d t}
\end{aligned}
$$

The above equation shows that the impressed voltage of the winding equals the voltage of the three parts of the driving circuit. The first term of the equation is the resistance voltage drop in the winding circuit; the second is the electromotive force induced by the flux linkage changes caused by the current excitation, that is, transformer electromotive force; the third is the electromotive force induced by the flux linkage changes in the winding caused by the rotating position, namely moving electromotive force, which is directly related to the electromechanical energy conversion. Thus, the current excitation of phase $k$ winding can be expressed as follows.

$$
i_{k}=\int \frac{U_{k}-R_{k} i_{k}-i_{k} \frac{d L_{k}\left(\theta, i_{k}\right)}{d t}}{L_{k}\left(\theta, i_{k}\right)} d t
$$

Furthermore, the electromagnetic characteristic of SRM under different driving conditions can be calculated according to the above expression and electromechanical coupling model in section 2.1 .

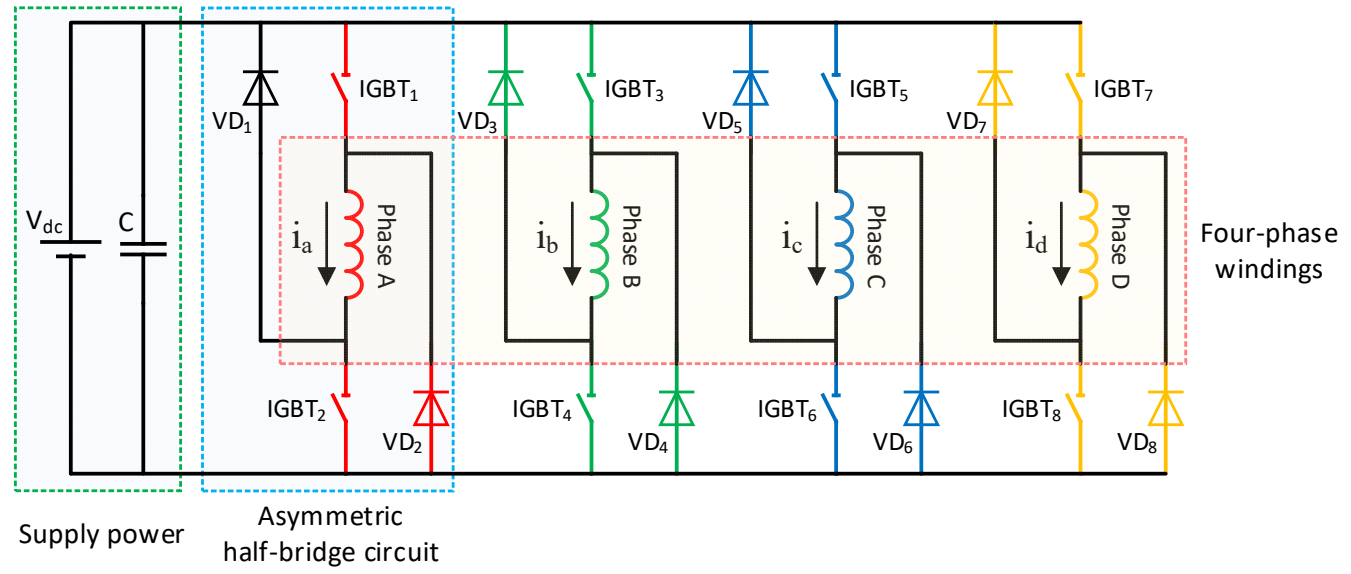

Fig. 4. Asymmetric half bridge power converter.

\subsection{Electromagnetic analysis under airgap eccentricity}

In order to quantify the level of airgap eccentricity between stator and rotor, the relative airgap 
eccentricity of SRM is defined as follows.

$$
\varepsilon=\left(\Delta g / l_{g}\right) \times 100 \%
$$

where $\Delta g$ is airgap eccentricity. The inductance and flux linkage under fixed current excitation and different airgap eccentricities are obtained according to the electromechanical magnetic coupling model and circuit driving equation, as shown in figure 5.

Combining equation (4) and (5), the magnetostatic torque of SRM under different airgap eccentricities is expressed as follows.

$$
T_{e}=\int_{0}^{i} \frac{\partial \psi(\theta, i)}{\partial \theta} d i=\sin \left(N_{r} \theta\right) \sum_{n=1}^{N} \frac{1}{n} e_{n-1} i_{k}^{n}+\sin \left(2 N_{r} \theta\right) \sum_{n=1}^{N} \frac{1}{n} f_{n-1} i_{k}^{n}
$$

where $e_{n}=N_{r} c_{n} / 2, e_{0}=0, e_{1}=N_{r}\left(c_{1}-L_{u}\right) / 2 ; f_{n}=N_{r} d_{n}-e_{n}, f_{0}=0, f_{1}=N_{r}\left(2 d_{1}-c_{1}-L_{u}\right) / 2$.

Further, ignoring end effect and winding mutual inductance, the radial electromagnetic force under different airgap eccentricities is approximately expressed as follows.

$$
F_{r}=\int_{0}^{i} \frac{\partial \psi(\theta, i)}{\partial l_{g}} d i=\frac{1}{2} \frac{L(\theta, i)}{l_{g}-\Delta g} i^{2}
$$

Similarly, the magnetostatic torque and radial electromagnetic force under different airgap eccentricities are shown in figure 6 . The peaks comparison results of electromagnetic characteristic and output response of SRM under different airgap eccentricities are shown in table 1.
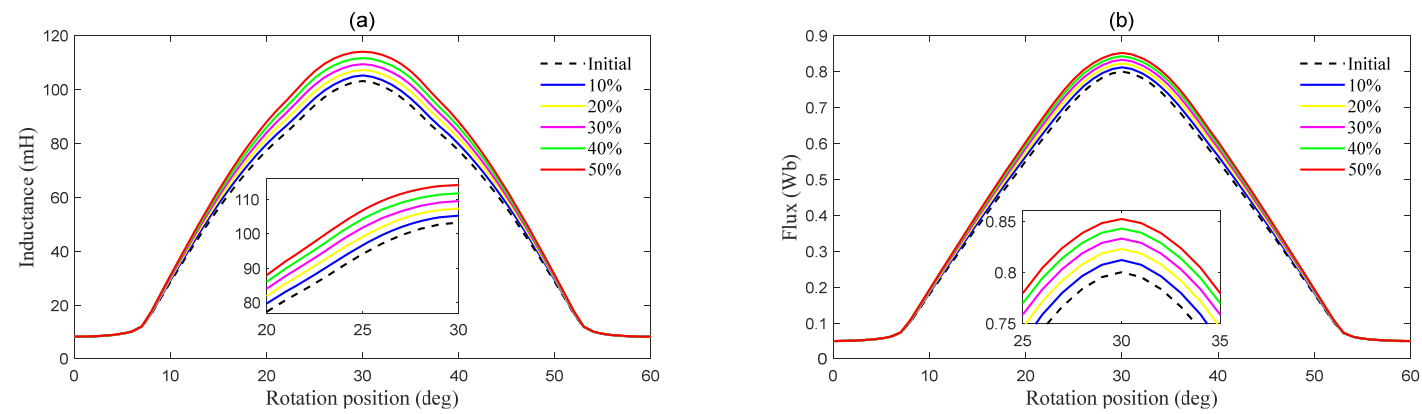

Fig. 5. Electromagnetic characteristic under different airgap eccentricities.

(a) inductance; (b) flux linkage.
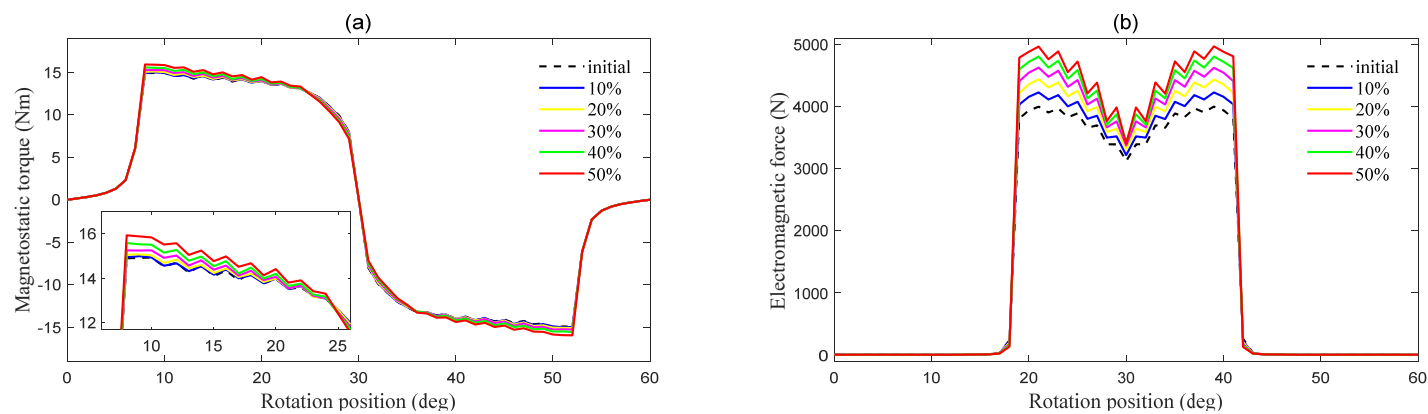

Fig. 6. Output response under different airgap eccentricities.

\begin{tabular}{|c|c|c|c|c|}
\hline / & Inductance / $\mathrm{mH}$ & Flux / Wb & Torque / Nm & Force / N \\
\hline Initial & 103.21 & 0.8003 & 14.93 & 4000 \\
\hline $10 \%$ & $105.26(\mathbf{1 . 9 9 \%})$ & $0.8121(\mathbf{1 . 4 7 \%})$ & $14.99(\mathbf{0 . 4 0 \%})$ & $4230(\mathbf{5 . 8 \%})$ \\
\hline $20 \%$ & $107.32(\mathbf{3 . 9 8 \%})$ & $0.8230(\mathbf{2 . 8 4 \%})$ & $15.08(\mathbf{1 . 0 0 \%})$ & $4440(\mathbf{1 1 . 0 \%})$ \\
\hline $30 \%$ & $109.45(\mathbf{6 . 0 5 \%})$ & $0.8331(\mathbf{4 . 1 0 \%})$ & $15.25(\mathbf{2 . 1 4 \%})$ & $4627(\mathbf{1 5 . 7 \%})$ \\
\hline $40 \%$ & $111.70(\mathbf{8 . 2 3 \%})$ & $0.8428(\mathbf{5 . 3 1 \%})$ & $15.58(4.35 \%)$ & $4806(\mathbf{2 0 . 2 \%})$ \\
\hline $50 \%$ & $114.09(\mathbf{1 0 . 5 4 \%})$ & $0.8520(6.46 \%)$ & $15.92(\mathbf{6 . 6 3 \%})$ & $4970(\mathbf{2 4 . 3 \%})$ \\
\hline
\end{tabular}

(a) magnetostatic torque; (b) radial electromagnetic force.

Table 1. The data comparison under different airgap eccentricities. 
Combined with the figure and table, it is obvious that the peaks of response data of SRM increase obviously with the aggravation of airgap eccentricity. The radial electromagnetic force has the most significant change, and its trend shows a linear increase with a slope of approximately 1. What is more, magnetostatic torque is the partial derivative of flux linkage with respect to rotating position according to equation (4), which results in the similarity of variation trend between the above varieties. In summary, the imbalance of radial electromagnetic force caused by airgap eccentricity on SRM should be e mphasized in engineering practice.

\section{Vibration analysis for in-wheel motor driving system}

In order to clarify the negative dynamics effect mechanism of in-wheel SRM driving system caused by airgap eccentricity, the quarter vehicle dynamics model was established on the basis of the coupling relationship between road excitation, airgap eccentricity and unbalanced radial force in this section.

\subsection{Quarter vehicle dynamics modeling}

The airgap eccentricity of SRM caused by road excitation is unavoidable, and the resulting unbalanced radial force will affect the dynamics response of in-wheel motor driving system. The quarter vehicle dynamics model established is shown in figure 7. Different from the traditional quarter vehicle dynamics model, this model splits the vehicle unsprung mass into $m_{s}$ (total mass of rotor, rim and tire) and $m_{r}$ (total mass of stator and housing), which are connected to each other by motor bearings and hub bearings, and the sum of their stiffness is $k_{r}$. All vehicle parameters are listed in appendix A.
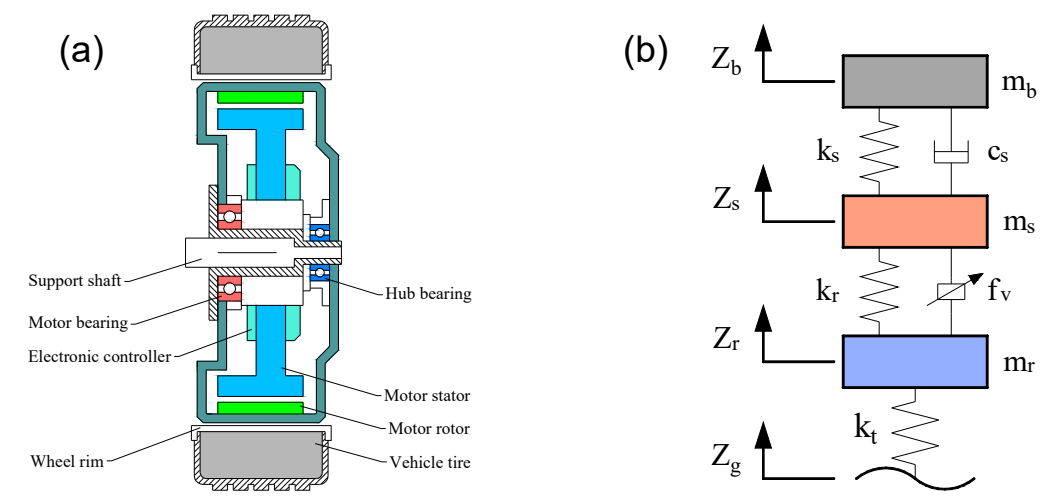

Fig. 7. In-wheel SRM driving system.

(a) assembly structure layout; (b) quarter vehicle dynamics model.

According to Newton's second law, the motion equation of the quarter vehicle dynamics model can be expressed as follows.

$$
\left\{\begin{array}{l}
m_{b} \ddot{z}_{b}=k_{s}\left(z_{s}-z_{b}\right)+c_{s}\left(\dot{z}_{s}-\dot{z}_{b}\right) \\
m_{s} \ddot{z}_{s}=k_{r}\left(z_{r}-z_{s}\right)-k_{s}\left(z_{s}-z_{b}\right)-c_{s}\left(\dot{z}_{s}-\dot{z}_{b}\right)-f_{v} \\
m_{r} \ddot{z}_{r}=k_{t}\left(z_{g}-z_{r}\right)-k_{r}\left(z_{r}-z_{s}\right)+f_{v}
\end{array}\right.
$$

where $z_{b}, z_{s}, z_{r}$ and $z_{g}$ is displacement of sprung mass, stator assembly, rotor assembly and road excitation respectively. $k_{t}, k_{s}$ and $c_{s}$ is tire stiffness, suspension stiffness and damping coefficient respectively. $m_{b}$ is sprung mass. $f_{v}$ is unbalanced radial force.

As vehicle vibration input, road roughness is mainly described by road power spectral density $G_{q}(n)$ and its fitting expression is as follow. 


$$
G_{q}(n)=G_{q}\left(n_{0}\right)\left(\frac{n}{n_{0}}\right)^{-w}
$$

where $n$ and $n_{0}$ is spatial frequency and reference spatial frequency respectively. $G_{q}\left(n_{0}\right)$ is the power spectral density value under the reference spatial frequency $n_{0}$, which is called the road roughness coefficient. $w$ is frequency index.

Taking filtered white noise road excitation as input and EV drive at $60 \mathrm{~km} / \mathrm{h}$ on class A and B road respectively, the variation of airgap eccentricity and unbalanced radial force of in-wheel motor driving system is shown in figure 8 . With the deterioration of road excitation, the airgap eccentricity and unbalanced radial force increase significantly. What is more, the airgap eccentricity will be further aggravated due to the mutual attraction of radial electromagnetic force between stator and rotor. The road excitation, airgap eccentricity and unbalanced radial force show positive correlation coupling.
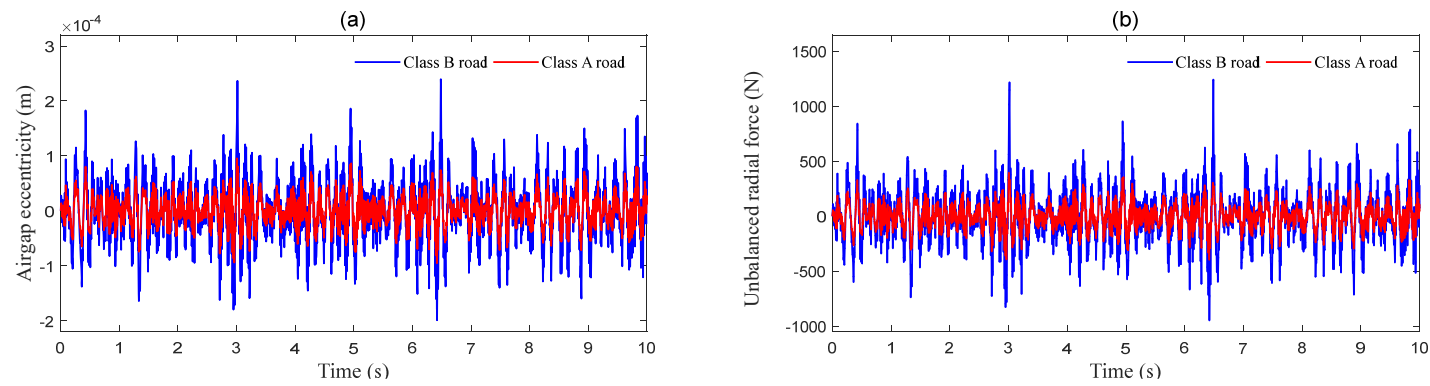

Fig. 8. Dynamic output response of in-wheel motor driving system.

(a) airgap eccentricity; (b) unbalanced radial force.

\subsection{Vibration mechanism analysis}

It is of theoretical significance to analyze the vibration mechanism of in-wheel motor driving system to suppress the negative dynamics effect. The quarter vehicle dynamics model can be expressed by the state-space equation as follows.

$$
\left\{\begin{array}{l}
\dot{\mathbf{x}}=\mathrm{A} \mathbf{x}+\mathrm{Bu} \\
\mathbf{y}=\mathrm{C} \mathbf{x}+\mathrm{Du}
\end{array}\right.
$$

First, each displacement and acceleration of the in-wheel motor driving system are defined as state vector.

$$
\mathbf{x}=\left[\begin{array}{llllll}
z_{b} & \dot{z}_{b} & z_{s} & \dot{z}_{s} & z_{r} & \dot{z}_{r}
\end{array}\right]^{\mathrm{T}}
$$

Then, unbalanced radial force and road excitation are selected as the state-space equation input vector.

$$
\mathbf{u}=\left[\begin{array}{llll}
0_{1 * 3} & f_{v} & z_{g} & \dot{z}_{g}
\end{array}\right]
$$

Finally, the state-space equation output vector is composed of sprung mass acceleration, suspension dynamic deflection and tire bounce.

$$
\mathbf{y}=\left[\begin{array}{lll}
\ddot{z}_{b} & z_{b}-z_{s} & z_{r}-z_{g}
\end{array}\right]^{\mathrm{T}}
$$

According to the above input and output vectors, the state-space equation system matrices are listed in appendix B. Energy decoupling is performed on the quarter vehicle dynamics model, and the vibration energy distribution and vibration modes are shown in table 2 and figure 9 (a). Furthermore, the transfer characteristics of in-wheel motor driving system with respect to unbalanced radial force are shown in figure 10. 
Table 2 Vibration energy distribution of the quarter vehicle dynamics model.

\begin{tabular}{cclll}
\hline modal order & natural frequency $(\mathrm{Hz})$ & $m_{b}(\%)$ & $m_{s}(\%)$ & $m_{r}(\%)$ \\
\hline $1^{\text {st }}$ mode & $\mathbf{1 . 2 4 0 0}$ & $\mathbf{9 9 . 7 7 5 4}$ & 0.2245 & 0.0001 \\
$2^{\text {nd }}$ mode & $\mathbf{8 . 1 9 1 7}$ & 0.0887 & 37.1344 & $\mathbf{6 2 . 7 7 6 9}$ \\
$3^{\text {th }}$ mode & $\mathbf{6 4 . 3 9 3 9}$ & 0.1359 & $\mathbf{6 2 . 3 4 1 1}$ & 37.5230 \\
\hline
\end{tabular}
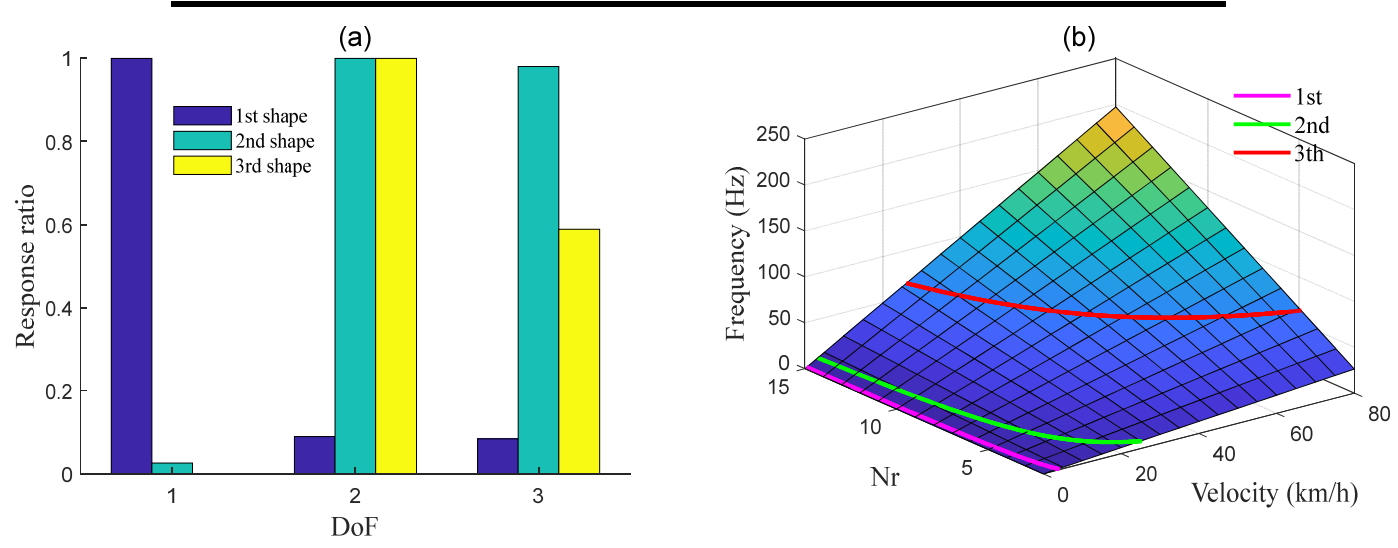

Fig. 9. Frequency domain analysis results of in-wheel motor driving system.

(a) quarter vehicle vibration modes; (b) radial electromagnetic force excitation frequency.

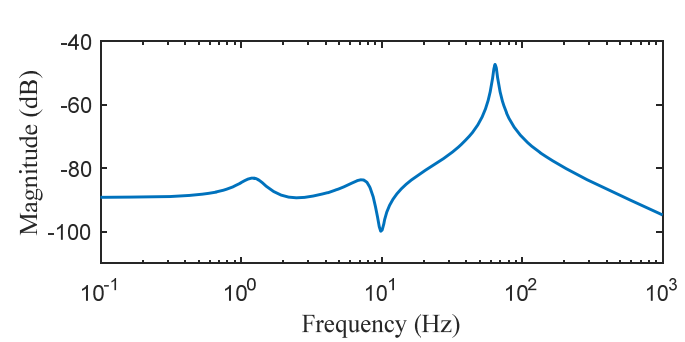

(a)

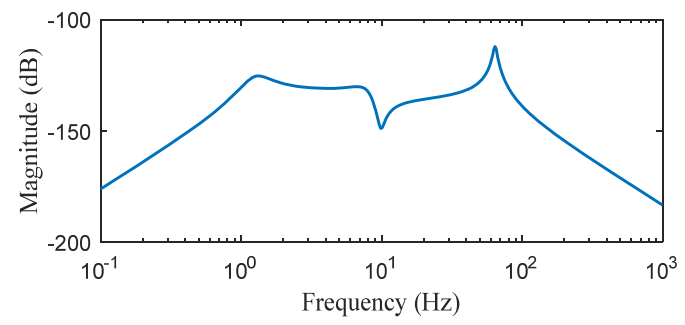

(b)
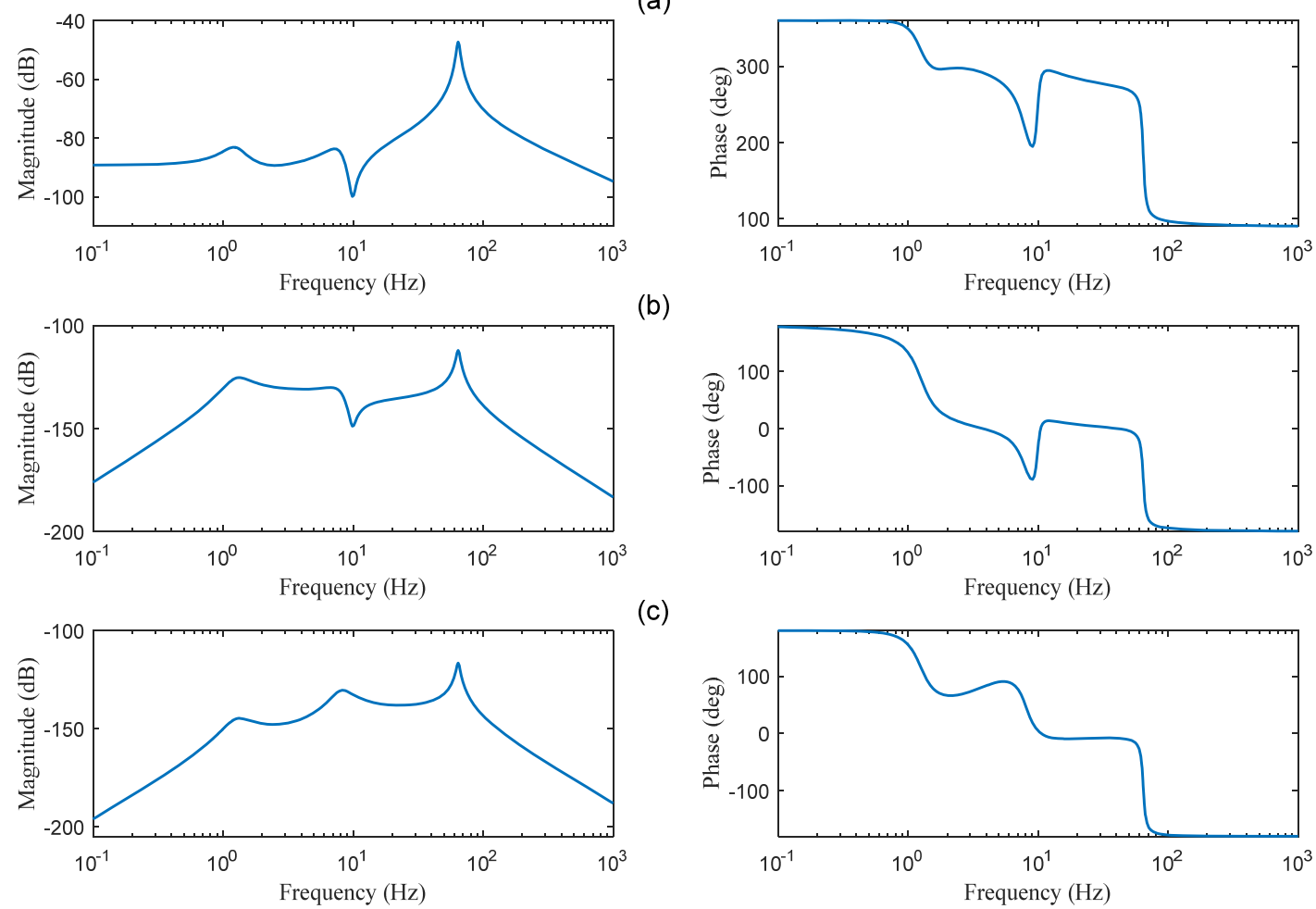

(c)

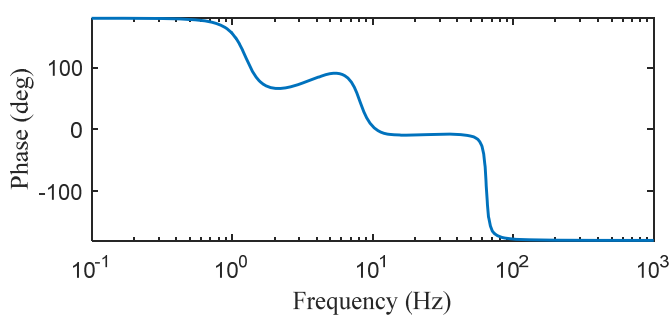

Fig. 10. Transfer characteristics of vehicle vibration to unbalanced radial force.

(a) sprung mass acceleration; (b) suspension dynamic deflection; (c) tire bounce.

The vibration modes of the in-wheel motor driving system concentrates on the $1^{\text {st }}$ order vibration of $1.24 \mathrm{~Hz}$ for sprung mass, the $2^{\text {nd }}$ order vibration of $8.19 \mathrm{~Hz}$ for rotor assembly and the $3^{\text {th }}$ order vibration of $64.39 \mathrm{~Hz}$ for stator assembly. In the $1^{\text {st }}$ order vibration, the vibration influence of unbalanced radial force is similar to the low-order vibration response caused by road excitation in the traditional quarter vehicle model, and its vibration energy is mainly concentrated on the vehicle sprung mass. In contrast, while the vibration response caused by road excitation is related 
to vehicle mass and suspension parameters, the vibration response caused by unbalanced radial force in concerned with airgap eccentricity and current excitation.

On the other hand, road excitation is generally random excitation, but unbalanced radial force is harmonic excitation with respect to driving speed and rotor salient pole number. The excitation frequency of unbalanced radial force can be approximated as follows.

$$
f_{e}=i_{g} \frac{n_{v}}{60} N_{r}=i_{g} \frac{\omega}{2 \pi} N_{r} \cong i_{g} \frac{v}{2 \pi R_{e}} \frac{N_{r}}{3.6}
$$

where $i_{g}$ is vehicle transmission ratio, $n_{v}$ is driving speed, $N_{r}$ is rotor salient pole number. The excitation frequency of unbalanced radial force under different salient pole number and driving speed is shown in the figure 9 (b).

Within the low driving speed, especially in the vehicle starting condition $(0-5 \mathrm{~km} / \mathrm{h})$, the unbalanced radial force excitation frequency is concentrated in the low-order frequency band, which has significant vibration influence on the vehicle riding comfort. In the $2^{\text {nd }}$ and $3^{\text {th }}$ order modes, the vertical vibration of the stator assembly and rotor assembly is main motion and there is mutual coupling between them. Moreover, the vibration energy is mainly concentrated on the unsprung mass of in these frequency bands, which indicates that in a higher frequency, the unbalanced radial force has a greater response on the unsprung mass.

In addition, since the SRM is installed directly in the rim and connected to the tire. The $2^{\text {nd }}$ order vibration energy distribution is larger in the unsprung mass rotor assembly at the vehicle low speed $(5-30 \mathrm{~km} / \mathrm{h})$. This frequency band is close to the tire resonance frequency, which deteriorates the road adhesion condition of tire and damages the wheel load distribution. In the common driving speed $(30-80 \mathrm{~km} / \mathrm{h})$, the unbalanced radial force excitation frequency varies widely. The vibration energy is concentrated in the unsprung mass stator assembly, which poses a serious threat to the structural stability of in-wheel motor.

\section{Formulation and optimization of Control strategy}

In order to alleviate the negative airgap eccentricity effect caused by unbalanced radial force, this section proposes an independent current chopping control strategy for in-wheel SRM driving system based on vehicle vibration feedback. Furthermore, aiming at the time-varying feature of driving speed, the controller parameters were optimized by interpolation in real time to achieve cooperative optimal performance between in-wheel motor driving system and EV.

\subsection{Control strategy formulation}

The commonly used control methods for SRM include angular position control (APC), current chopping control (CCC) and pulse width modulation control (PWM), and these control methods limit the motor electromagnetic characteristics by adjusting the current excitation. On the other hand, the unbalanced radial force can be expressed as a quadratic polynomial about the current excitation. Limiting the current excitation can effectively suppress the negative airgap eccentricity effect of inwheel SRM driving system.

Based on the above three control methods, this section takes the vehicle sprung mass acceleration and driving speed error as the feedback signal, the turn-on angle and turn-off angle are selected as $5^{\circ}$ and $25^{\circ}$ respectively, and the chopping current threshold is set as $22 \mathrm{~A}$. At the same time, the voltage duty cycle is calculated by PID controller according to the driving torque required by the vehicle, which is called control strategy $\mathrm{A}$. 
Furthermore, chopping the current excitation will inevitably lead to the decrease of driving torque and thus affect the vehicle dynamics performance. From the perspective of vehicle driving conditions, it is conspicuous that most of the airgap eccentricity occurs at the vertical phase affected by the wheel load and road excitation. In order to increase the maximum driving torque of the inwheel SRM driving system, this section proposes control strategy B by ameliorating control strategy A.

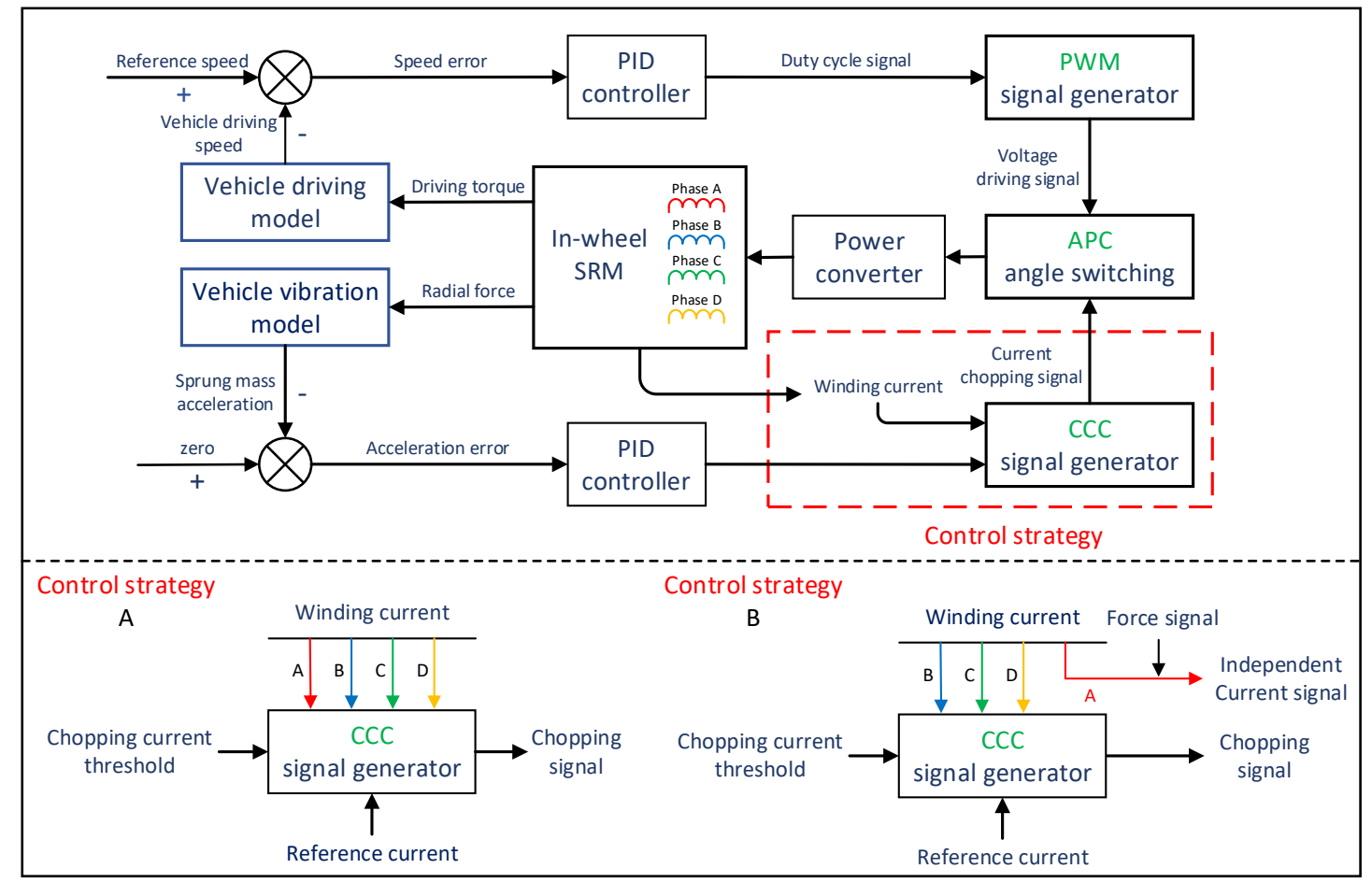

Fig. 11. Logical control strategy framework.

The control strategy B implements independent control for each current excitation, chopping the current on the phase where the unbalanced radial force exists, and only sets the protection current threshold on the remaining phases. The unbalanced radial force of in-wheel motor can be reduced while the driving torque can meet the demand of vehicle dynamics performance. The logical frameworks of control strategy are shown in figure 11.

\subsection{Control strategy implementation}

Taking EV drive at $20 \mathrm{~km} / \mathrm{h}$ on Class B road and the phase A winding is the vertical phase of in-wheel motor driving system. The response results under different control strategies are shown in figure 12 and 13. The driving torque of in-wheel motor driving system under control strategy B is obviously better than control strategy A. In addition, the unbalanced radial force under both control strategies is basically at the same level, and it does not deteriorate due to the independent chopping of winding current. 

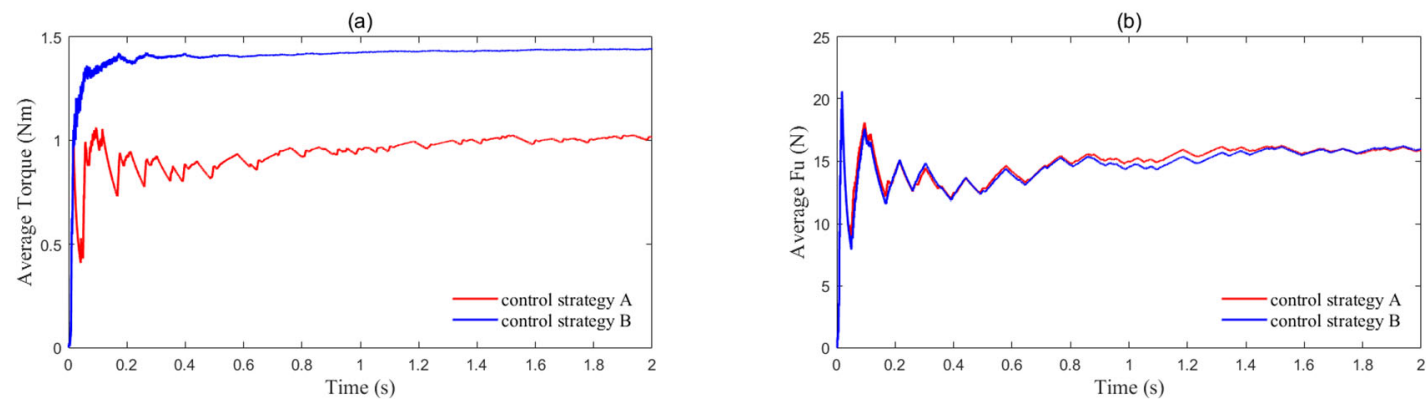

Fig. 12. Control results of in-wheel motor driving system.

(a) driving torque; (b) unbalanced radial force.
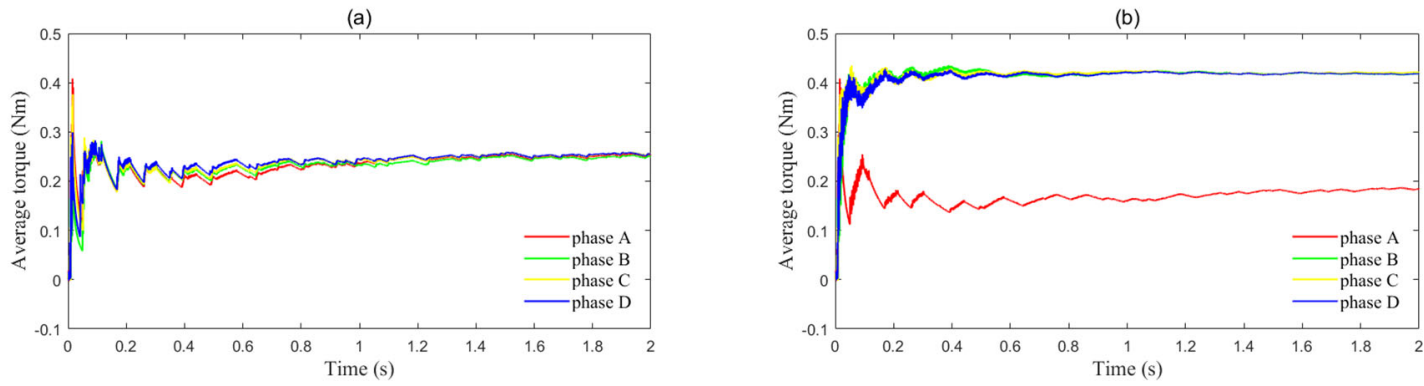

Fig. 13. Average torque under different driving torque.

(a) control strategy A; (b) control strategy B.

The vehicle driving speed error and average voltage duty cycle under different control strategy are shown in figure 14. It is obvious that the average voltage duty ratio under control strategy A is larger than that under control strategy $\mathrm{B}$, but the increase of duty ratio cannot effectively compensate for the driving torque loss caused by winding current chopping. As a result, the vehicle driving speed error under the control strategy A is greater because of the shortage of driving torque. In summary, through the independent current chopping control of in-wheel SRM driving system, the unbalanced radial force can be suppressed while the driving torque can be improved to guarantee the vehicle power.
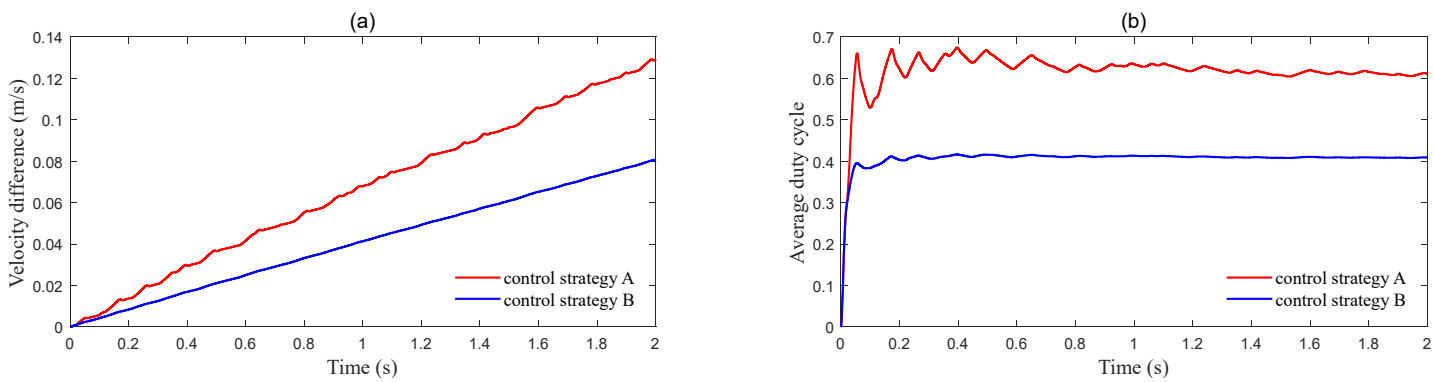

Fig. 14. Control results under different strategy.

(a) driving velocity error; (b) average duty cycle.

\subsection{Control strategy optimization}

Based on the above analysis, it can be seen that both unbalanced radial force and driving torque are positively correlated with current excitation, so how to achieve the maximum driving torque while suppressing unbalanced radial force has become an urgency to be solved. More importantly, the vehicle often faces the demand of changing driving speed, especially in the starting condition, it is difficult to achieve cooperative optimal performance of in-wheel motor driving system and EV 
under fixed controller parameters. To solve the above problems, this section takes the vehicle acceleration as feedback signal and selects the controller parameters in different driving speed interval through interpolation to realize the optimum control of negative airgap eccentricity effect of in-wheel motor driving system.

Setting the vehicle driving speed to accelerate from $0 \mathrm{~m} / \mathrm{s}$ to $5 \mathrm{~m} / \mathrm{s}$ within $4 \mathrm{~s}$. Since the driving speed and acceleration are low in this case, road excitation can be ignored. Linear interpolation and spline interpolation are respectively adopted to screen the turn-off angle and chopping current threshold, so as to suppress the minimum radial force and the maximum driving torque on the premise of improving vehicle riding comfort.
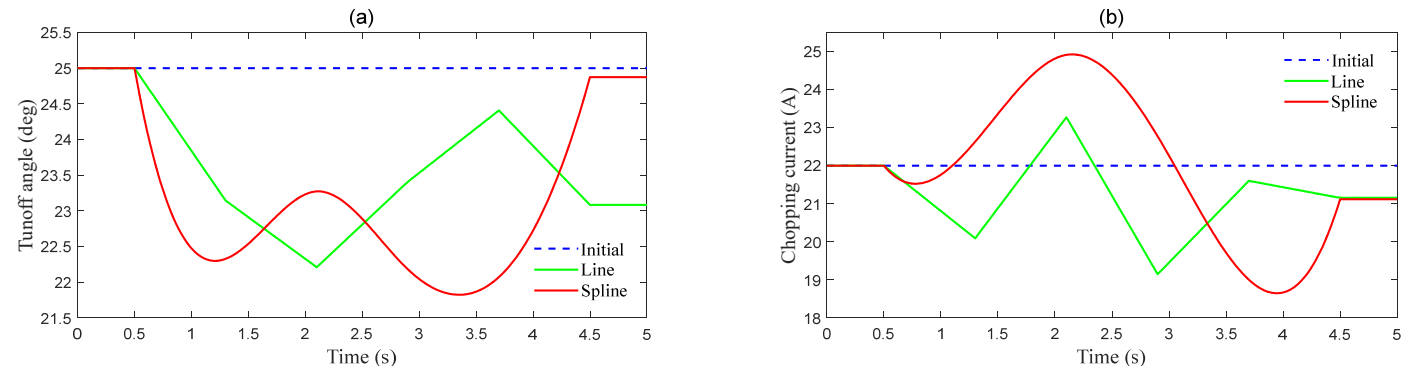

Fig. 15. Real-time controller parameters.

(a) turn-off angle; (b) chopping current.
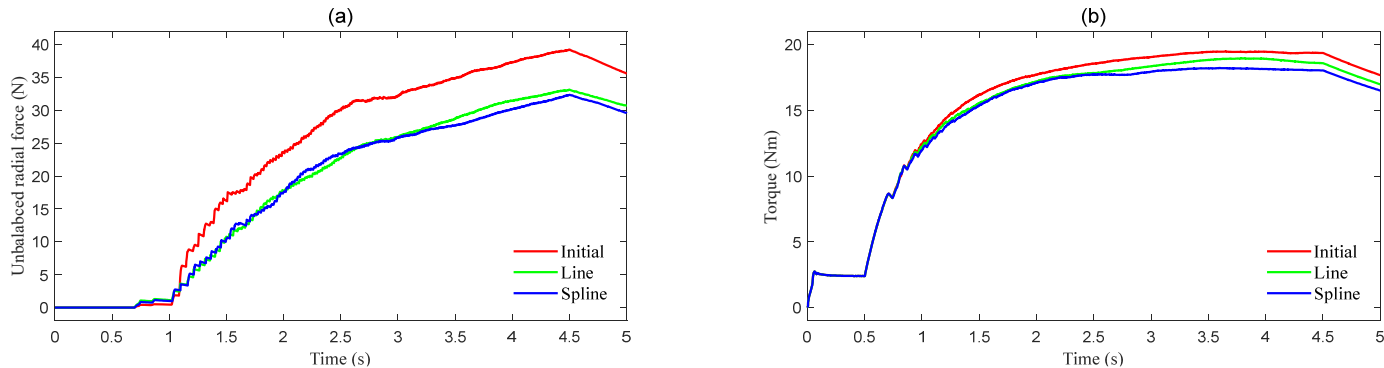

Fig. 16. Output response of in-wheel motor driving system.

(a) unbalanced radial force; (b) driving torque.

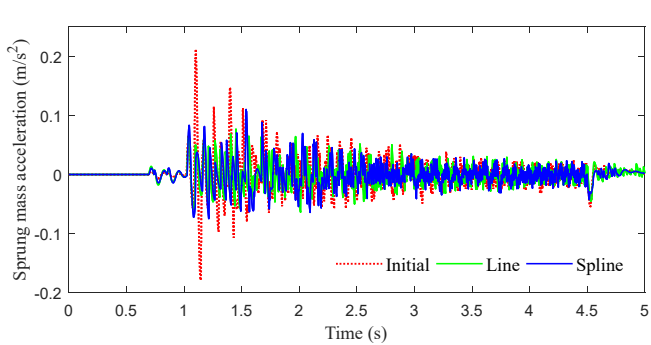

(a)
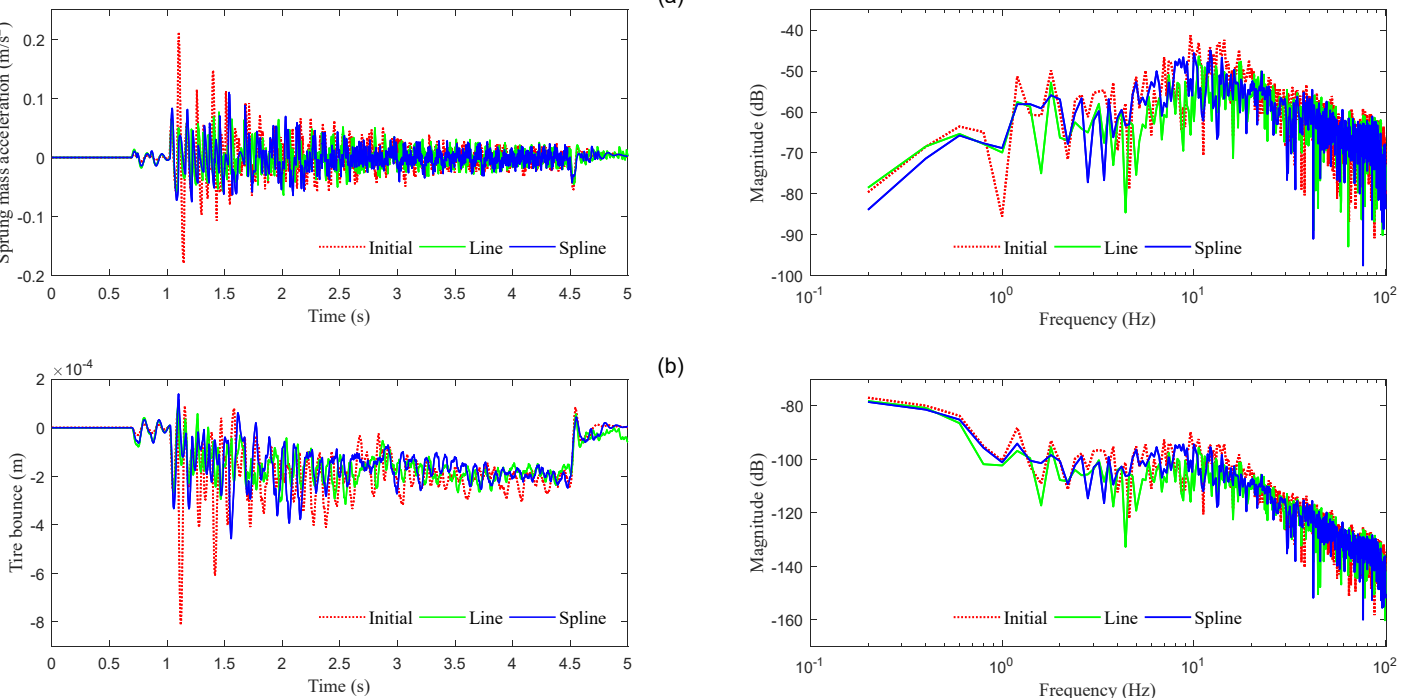

(b)

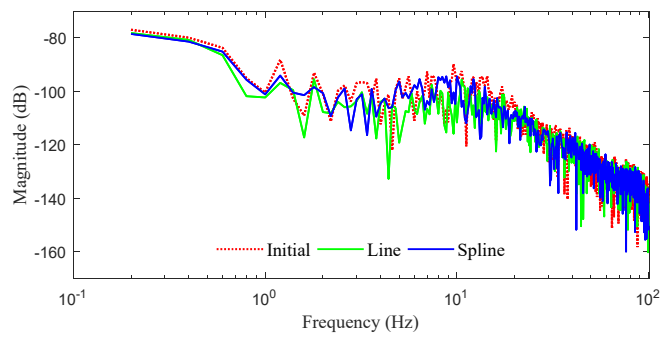

Fig. 17. Dynamics performance of EV.

(a) sprung mass acceleration; (b) tire bounce. 
Table 3. Comparison of simulation results

\begin{tabular}{ccccc}
\hline & $\begin{array}{c}\text { Unbalanced radial force } \\
(\mathrm{N})\end{array}$ & $\begin{array}{c}\text { Driving torque } \\
(\mathrm{Nm})\end{array}$ & $\begin{array}{c}\text { Sprung mass acceleration } \\
\left(\mathrm{m} / \mathrm{s}^{2}\right)\end{array}$ & $\begin{array}{c}\text { Tire bounce } \\
(\mathrm{mm})\end{array}$ \\
\hline Initial & 27.48 & 16.56 & 0.0282 & 0.1882 \\
Line & $22.35(-18.67 \%)$ & $16.01(-3.32 \%)$ & $0.0177(37.23 \%)$ & $0.1503(20.14 \%)$ \\
Spline & $21.91(-20.26 \%)$ & $15.65(-5.50 \%)$ & $0.0201(28.72 \%)$ & $0.1525(18.97 \%)$ \\
\hline
\end{tabular}

The real-time controller parameters obtained by linear interpolation and spline interpolation are shown in figure 15. Compared with the fixed controller parameters, the interpolated controller parameters can improve the output response of in-wheel SRM system and the dynamics performance of EV. The simulation results are shown in figure 16, figure 17 and table 3 .

In the output response of in-wheel motor driving system, the RMS value of unbalanced radial force decreases by $18.67 \%$ and $20.26 \%$ respectively under linear interpolation and spline interpolation control. Due to the response conflict between unbalanced radial force and driving torque, the increase of one term will inevitably lead to the decrease of another term. The driving torque of in-wheel motor driving system is sacrificed $3.32 \%$ and $5.50 \%$ respectively under different interpolation methods. Combined with the figure, it can be seen that both unbalanced radial force and driving torque decrease during vehicle running, but the sacrificing of driving torque is far worth that the suppression of unbalanced radial force.

The dynamics performance of EV after optimum control is also improved, and its sprung mass acceleration RMS value decreases by $37.23 \%$ and $28.72 \%$ respectively, especially the sprung mass acceleration shock when the vehicle starts is well restrained. Correspondingly, the tire bounce is also well suppressed. Since the airgap length of in-wheel motor is very small, for example, the airgap of the SRM studied in this paper is only $0.5 \mathrm{~mm}$. The reduction of tire bounce plays an important role in the structural impact of in-wheel motor.

\section{Conclusions}

This article focuses on the negative airgap eccentricity effect of in-wheel SRM driving system. First, the electromagnetic characteristic and output response of SRM under airgap eccentricity are explored. Then, according to the coupling relationship between road excitation, airgap eccentricity and unbalanced radial force, the vibration analysis in time domain and frequency domain is carried out for in-wheel motor driving system. Finally, an independent current chopping control strategy of in-wheel SRM driving system based on vehicle vibration feedback is proposed. The main contributions of this paper are as follows.

1. The electromagnetic characteristic and output response of SRM are highly nonlinear, and its magnitude varies nonlinearly with the rotating position and current excitation. The existence of airgap eccentricity will lead to the improvement of magnetostatic torque and radial electromagnetic force, among which the radial electromagnetic force has the most obvious change.

2. There is a positive coupling relationship between road excitation, airgap eccentricity and unbalanced radial force. With the increase of road excitation, airgap eccentricity and unbalanced radial force will increase significantly. Furthermore, the vibration analysis of in-wheel motor driving system is carried out based on the excitation characteristics of unbalanced radial force. The unbalanced radial force will affect the vehicle sprung mass at low frequency and the vibration response at middle and high frequencies will focus on the vehicle unsprung mass. 
3. The proposed independent current chopping control strategy for the in-wheel motor driving system can effectively improve the driving torque while suppressing the unbalanced radial force by controlling the current excitation. Furthermore, in order to meet the time-varying feature of driving speed, the controller parameters are optimized by interpolation with vehicle acceleration as feedback signal. Simulation results show that this control strategy can achieve the cooperative optimal output between in-wheel motor driving system and vehicle dynamics performance.

This paper focuses on the mechanism analysis and optimum control of the negative airgap eccentricity effect for in-wheel SRM driving system, laying an engineering foundation for the promotion and application of EVs driven by in-wheel motor.

\section{Acknowledgements}

This research was supported by the National Natural Science Foundation of China (Grant no. 52072054), the Science and Technology Research Program of Chongqing Municipal Education Commission (KJQN202100728), the Technology Innovation and Application Development of Chongqing Municipality (cstc2019jscx-zdztzxX0047), the Postgraduate Scientific Research Innovation Program of Chongqing Municipality (CYS21358).

\section{Data availability statements}

The datasets generated during and/or analysed during the current study are available from the corresponding author on reasonable request. 
Appendix A. Parameters of SRM and EV.

\begin{tabular}{ccccc}
\hline parameter & value & unit & expression \\
\hline$D_{r}$ & 382 & $\mathrm{~mm}$ & SRM & Outer diameter of rotor \\
$D_{s}$ & 266 & $\mathrm{~mm}$ & Outer diameter of stator \\
$\beta_{r}$ & 23 & $\mathrm{deg}$ & Rotor pole arc angle \\
$\beta_{s}$ & 22 & $\mathrm{deg}$ & Stator pole arc angle \\
$L_{g}$ & 0.5 & $\mathrm{~mm}$ & Airgap length \\
$L_{s}$ & 46 & $\mathrm{~mm}$ & Thickness of stator back iron \\
$L_{r}$ & 32 & $\mathrm{~mm}$ & Thickness of rotor back iron \\
$H$ & 74 & $\mathrm{~mm}$ & Stack length \\
$N$ & 136 & $/$ & Number of turns per phase \\
\hline$m_{b}$ & 337.5 & $\mathrm{~kg}$ & $\mathbf{E V}$ & Sprung mass of vehicle \\
$m_{s}$ & 37.5 & $\mathrm{~kg}$ & Total mass of stator and shell \\
$m_{r}$ & 65 & $\mathrm{~kg}$ & Total mass of rotor and tire \\
$c_{s}$ & 1450 & $\mathrm{Ns} / \mathrm{m}$ & Suspension damping \\
$k_{s}$ & 23500 & $\mathrm{~N} / \mathrm{m}$ & Suspension stiffness \\
$k_{t}$ & 250000 & $\mathrm{~N} / \mathrm{m}$ & Tire stiffness \\
$k_{r}$ & 3850000 & $\mathrm{~N} / \mathrm{m}$ & & motor and hub bearing stiffness \\
\hline
\end{tabular}

Appendix B. State-space equation system matrices.

$$
\begin{aligned}
& \mathrm{A}=\left[\begin{array}{cccccc}
0 & 1 & 0 & 0 & 0 & 0 \\
-k_{s} m_{b}^{-1} & -c_{s} m_{b}^{-1} & k_{s} m_{b}^{-1} & c_{s} m_{b}^{-1} & 0 & 0 \\
0 & 0 & 0 & 1 & 0 & 0 \\
k_{s} m_{s}^{-1} & c_{s} m_{s}^{-1} & -\left(k_{r}+k_{s}\right) m_{s}^{-1} & -c_{s} m_{s}^{-1} & k_{r} m_{s}^{-1} & 0 \\
0 & 0 & 0 & 0 & 0 & 1 \\
0 & 0 & k_{r} m_{r}^{-1} & 0 & -\left(k_{t}+k_{r}\right) m_{r}^{-1} & -c_{t} m_{r}^{-1}
\end{array}\right] ; \\
& \mathrm{B}=\left[\begin{array}{cccc}
0_{3^{* 3}} & & 0_{3^{* 3}} & \\
& -m_{s}^{-1} & 0 & 0 \\
0_{3^{* 3}} & 0 & 0 & 0 \\
& m_{r}^{-1} & k_{t} m_{r}^{-1} & c_{t} m_{r}^{-1}
\end{array}\right] \text {; } \\
& \mathrm{C}=\left[\begin{array}{cccccc}
-k_{s} m_{b}^{-1} & -c_{s} m_{b}^{-1} & k_{s} m_{b}^{-1} & c_{s} m_{b}^{-1} & 0 & 0 \\
1 & 0 & -1 & 0 & 0 & 0 \\
0 & 0 & 0 & 0 & 1 & 0 \\
& & 0 & 0 & &
\end{array}\right] \\
& \mathrm{D}=\left[\begin{array}{cccccc}
\multicolumn{7}{c}{0_{3^{*} 6}} & & \\
0 & 0 & 0 & 0 & -1 & 0 \\
& & 0_{2^{*} 6} & & &
\end{array}\right] \text {. }
\end{aligned}
$$




\section{References}

1. Fernandes, J.C.M., Gonçalves, P.J.P., Silveira, M.: Interaction between asymmetrical damping and geometrical nonlinearity in vehicle suspension systems improves comfort. NONLINEAR DYNAM, 99(2), 1561-1576 (2020)

2. Rezig, A., Boudendouna, W., Djerdir, A., N Diaye, A.: Investigation of optimal control for vibration and noise reduction in-wheel switched reluctance motor used in electric vehicle. MATH COMPUT SIMULAT, 167, 267-280 (2020)

3. Li, Y., Sun, W., Huang, J., Zheng, L., Wang, Y.: Effect of vertical and lateral coupling between tyre and road on vehicle rollover. VEHICLE SYST DYN, 51(8), 1216-1241 (2013)

4. Jamil, M.U., Kongprawechnon, W., Chayopitak, N.: Active fault diagnosis of a switched reluctance motor using sliding mode observer and average torque estimator for light electric vehicle applications. INT T ELECTR ENERGY, 30(11) (2020)

5. Pomponi, C., Scalzi, S., Pasquale, L., Verrelli, C.M., Marino, R.: Automatic motor speed reference generators for cruise and lateral control of electric vehicles with in-wheel motors. CONTROL ENG PRACT, 79, 126-143 (2018)

6. Zhang, D., Qi, T., Wang, S., Ling, Z.: Effect of series/parallel circuits of eccentric switched reluctance motor on vehicle ride comfort. J BRAZ SOC MECH SCI, 43(4) (2021)

7. Sun, X., Wan, B., Lei, G., Tian, X., Guo, Y., Zhu, J.: Multiobjective and Multiphysics Design Optimization of a Switched Reluctance Motor for Electric Vehicle Applications. IEEE T ENERGY CONVER, (2021)

8. Chen, X., Chen, R., Deng, T.: An investigation on lateral and torsional coupled vibrations of high power density PMSM rotor caused by electromagnetic excitation. NONLINEAR DYNAM, 99(3), 1975-1988 (2020)

9. Chen, X., Deng, Z., Hu, J., Deng, T.: An analytical model of unbalanced magnetic pull for PMSM used in electric vehicle: Numerical and experimental validation. INT J APPL ELECTROM, 54(4), 583-596 (2017)

10. Zhu, Y., Wu, H., Zhen, C.: Regenerative braking control under sliding braking condition of electric vehicles with switched reluctance motor drive system. ENERGY, 230, 120901 (2021)

11. Wang, Y., Li, Y., Sun, W., Zheng, L.: Effect of the unbalanced vertical force of a switched reluctance motor on the stability and the comfort of an in-wheel motor electric vehicle. Proceedings of the Institution of Mechanical Engineers, Part D: Journal of Automobile Engineering, 229(12), 15691584 (2015)

12. Liu, F., Xiang, C., Liu, H., Han, L., Wu, Y., Wang, X.: Nonlinear vibration of permanent magnet synchronous motors in electric vehicles influenced by static angle eccentricity. NONLINEAR DYNAM, 90(3), 1851-1872 (2017)

13. Zuo, S., Liu, Z., Hu, S.: Influence of Rotor Eccentricity on Radial Electromagnetic Force Characteristics in Switched Reluctance Motors and Compensation. ELECTR POW COMPO SYS, 48(4-5), 388-398 (2020)

14. Hu, S., Zuo, S., Liu, M., Wu, H., Liu, Z.: Modeling and analysis of radial electromagnetic force and vibroacoustic behaviour in switched reluctance motors. MECH SYST SIGNAL PR, 142, 106778 (2020)

15. Wang, Y., Li, P., Ren, G.: Electric vehicles with in-wheel switched reluctance motors: Coupling effects between road excitation and the unbalanced radial force. J SOUND VIB, 372, 69-81 (2016)

16. Torkaman, H., Afjei, E., Yadegari, P.: Static, Dynamic, and Mixed Eccentricity Faults Diagnosis in 
Switched Reluctance Motors Using Transient Finite Element Method and Experiments. IEEE T MAGN, 48(8), 2254-2264 (2012)

17. Li, Z., Zheng, L., Ren, Y., Li, Y., Xiong, Z.: Multi-objective optimization of active suspension system in electric vehicle with In-Wheel-Motor against the negative electromechanical coupling effects. MECH SYST SIGNAL PR, 116, 545-565 (2019)

18. Ahmed, F., Kalita, K., Nemade, H.B.: Torque and controllable radial force production in a single winding bearingless switched reluctance motor with a speed controlled drive operation. INT T ELECTR ENERGY, 30(5) (2020)

19. Chen, X., Yuan, S., Peng, Z.: Nonlinear vibration for PMSM used in HEV considering mechanical and magnetic coupling effects. NONLINEAR DYNAM, 80(1-2), 541-552 (2015)

20. Tan, D., Lu, C.: The Influence of the Magnetic Force Generated by the In-Wheel Motor on the Vertical and Lateral Coupling Dynamics of Electric Vehicles. IEEE T VEH TECHNOL, 65(6), 4655-4668 (2016)

21. Sun, W., Li, Y., Huang, J., Zhang, N.: Vibration effect and control of In-Wheel Switched Reluctance Motor for electric vehicle. J SOUND VIB, 338, 105-120 (2015)

22. Shao, X., Naghdy, F., Du, H., Qin, Y.: Coupling effect between road excitation and an in-wheel switched reluctance motor on vehicle ride comfort and active suspension control. J SOUND VIB, 443, 683-702 (2019)

23. Li, Z., Zheng, L., Gao, W., Zhan, Z.: Electromechanical Coupling Mechanism and Control Strategy for In-Wheel-Motor-Driven Electric Vehicles. IEEE T IND ELECTRON, 66(6), 4524-4533 (2019)

24. Deng, Z., Li, X., Liu, T., Zhao, S.: Modeling and suppression of unbalanced radial force for in-wheel motor driving system. J VIB CONTROL, 1802379084 (2021)

25. Qin, Y., He, C., Shao, X., Du, H., Xiang, C., Dong, M.: Vibration mitigation for in-wheel switched reluctance motor driven electric vehicle with dynamic vibration absorbing structures. J SOUND VIB, 419, 249-267 (2018)

26. Xiong, S.: Study on Optimization Technology of Instantaneous Torque Control Strategy for Switched Reluctance Motor. Chemical engineering transactions, 66 (2018)

27. Xue, X.D., Cheng, K.W.E., Ng, T.W., Cheung, N.C.: Multi-Objective Optimization Design of InWheel Switched Reluctance Motors in Electric Vehicles. IEEE T IND ELECTRON, 57(9), 29802987 (2010)

28. Khalil, A., Husain, I.: A Fourier Series Generalized Geometry-Based Analytical Model of Switched Reluctance Machines. IEEE T IND APPL, 43(3), 673-684 (2007)

29. Fahimi, B., Suresh, G., Mahdavi, J., Ehsami, M.: A new approach to model switched reluctance motor drive application to dynamic performance prediction, control and design, 1998. IEEE, p 2097-2102. (1998)

30. Ma, C., Qu, L.: Multiobjective Optimization of Switched Reluctance Motors Based on Design of Experiments and Particle Swarm Optimization. IEEE T ENERGY CONVER, 30(3), 1144-1153 (2015). 